\title{
Nurses in the provision of outpatient care for women with malignant fungating wounds in the breasts
}

\author{
Enfermeiras no atendimento ambulatorial a mulheres com feridas neoplásicas malignas nas \\ mamas
}

\section{Enfermeras en la atención en el ambulatorio a mujeres con heridas neoplásicas malignas en las mamas}

\author{
Flávia Firmino ${ }^{1}$, Laísa Figueiredo Ferreira Lós Alcântara ${ }^{1}$
}

This study aimed to analyze accounts of nurses who undertake the dressing of fungating wounds of women with breast cancer, and to outline contributions to the nursing care. This is qualitative research, carried out in November 2010 with interviews and thematic analysis involving five nurses from the outpatient department of a public hospital in the city of Rio de Janeiro, specializing in the treatment of breast cancer. Categories were elaborated corresponding to the practice of outpatient nursing; the cancer wound; and, indications for the nursing care. It is concluded that there is a need for specific knowledge in the area of oncology nursing, professional involvement, technical skill and autonomy, the forming of a therapeutic group, clinical attendance interfacing with the palliative approach, and collaborative work as a team.

Descriptors: Oncologic Nursing; Breast Neoplasms; Outpatient Clinics, Hospital; Nursing Care.

Os objetivos desta pesquisa foram analisar relatos de enfermeiros que realizam curativos em feridas neoplásicas de mulheres acometidas pelo câncer de mama e traçar contribuições para a assistência de enfermagem. Trata-se de pesquisa qualitativa, realizada em novembro de 2010, com entrevistas e análise temática envolvendo cinco enfermeiras do ambulatório de um hospital público da cidade do Rio de Janeiro, Brasil, especializado no tratamento do câncer de mama. Foram elaboradas categorias correspondentes à prática de enfermagem ambulatorial; ferida neoplásica; apontamentos para a assistência de enfermagem. Há necessidade de conhecimentos específicos na área da enfermagem oncológica, envolvimento profissional, habilidade técnica e autonomia, realização de grupo terapêutico, atendimento clínico em interface com abordagem paliativa, e trabalho colaborativo em equipe.

Descritores: Enfermagem Oncológica; Neoplasias da Mama; Ambulatório Hospitalar; Cuidados de Enfermagem.

Los objetivos de esta investigación fueron analizar el relato de enfermeros que realizan curas en heridas neoplásicas de mujeres afectadas por cáncer de mama, e trazar las contribuciones a la práctica de la atención de enfermería. Investigación cualitativa, llevada a cabo en noviembre de 2010, con entrevistas semiestructuradas y análisis temático, con cinco enfermeras que actuaban en área ambulatoria de hospital público del Rio de janeiro, Brasil, especializado en tratamiento oncológico. Fueron desarrolladas categorías que correspondieron a la práctica de la enfermería ambulatoria; herida neoplásica; y notas para la atención de enfermería. Hay la necesidad de conocimientos específicos en enfermería oncológica, participación profesional, habilidad técnica y autonomía, equipos de discusión terapéutica y atención clínica en interfaz con enfoque paliativo y trabajo colaborativo en equipo.

Descriptores: Enfermería Oncológica; Neoplasias de la Mama; Servicio Ambulatorio en Hospital; Cuidados de Enfermería.

\footnotetext{
${ }^{1}$ Instituto Nacional de Câncer. Rio de Janeiro, RJ, Brazil. 


\section{Introduction}

Malignant cancer wounds result from the skin being broken by the infiltration of cancerous cells. They present as ulcerated wounds, either shallow or deep, which may or may not present a crater-like or cauliflower-like appearance. They progress to profuse exudate, friability, pain and a fetid odor. The site of the breast presents the highest incidence of this type of wound $^{(1)}$. The worsening of the symptoms resulting from these wounds significantly impoverishes the quality of life of the women who experience the process of becoming ill through cancer ${ }^{(1-2)}$. Indeed, the biggest problem identified in relation to these is the management of the control of the symptoms, which remains a true challenge for the patients, family members and health professionals ${ }^{(1-3)}$.

This issue has been little explored in literature around the world. In Brazil, the few studies made are predominantly in the mode of bibliographic reviews ${ }^{(4)}$. In the international context, researchers such as those led by Sebastian Probst, a nurse-researcher of the Department of Health at the University of Zürich in Switzerland have undertaken studies investigating the universe of patients ${ }^{(3)}$, family members ${ }^{(5)}$ and nurses ${ }^{(1)}$ involved directly with people with cancer who develop malignant fungating wounds. Such studies have evidenced the intense existential suffering experienced by patients with these wounds and by their family members, as well as the impotence and the technical lack of preparation of nurses assisting this clientele in the day-to-day of their professional activities.

Exploring this issue with original research is necessary and timely, due to the significant increases in the rates of both incidence and survival of cancer, with emphasis on breast cancer. For many, breast cancer has become a chronic, slowly-progressive disease $^{(1)}$, imposing a greater length of coexistence with the wound. This epidemiological and clinical phenomenon highlights the problem of the control of the malignant fungating wounds' symptoms, which requires attention from health professionals ${ }^{(6)}$.

Considering that this is a relevant issue for the routine practice of nursing, in the field of oncology and women's health, this study established as its aims to analyze the accounts of nurses who undertake the dressing of fungating wounds in women with breast cancer, and to outline contributions to the nursing care.

\section{Method}

This research with a qualitative approach was undertaken through interviews in the form of a Focus Group. This is a technique which employs a collective interview, mobilizing discussion of specific issues through the integration of people in the form of groups. It is also designated as group or collective interviewing ${ }^{(7)}$. It was carried out in a federal public hospital in the city of Rio de Janeiro which specializes in the treatment of breast cancer.

For data collection, a semi-structured script made up of two parts was used as the instrument: the first contained the following socio-demographic data: age, sex, time since qualification and length of professional experience. The second contained three questions which guided the discussion, the first being: "Talk to me about the experience of working applying dressings to the fungating wounds of women with breast cancer". The second question was: "What can you say regarding fungating wounds?", and the last question was: "What can you suggest for the nursing care practice carried out with these women?".

The operationalization of the data collection occurred during a single session which took place in November 2010, lasting approximately 60 minutes in a private room previously set aside for this purpose, so as to avoid interruptions and erroneous perceptions regarding the processes of recording and transcribing the interview, which was captured using an MP3 digital voice recorder and was later transcribed onto paper, where notes on the perceptions of two researchers who co-ordinated the group were also included, so 
as to reconstruct the emotions presented during the discussion $^{(7)}$.

The inclusion criteria for the research were: to be a nurse and to have worked for a period equal to or greater than six months applying dressings to the fungating wounds of women with breast cancer. The study sample was defined as the nurses working in the dressings room of the outpatients department, due to the fact that in this setting, nursing consultations take place which include the application of dressings to the fungating wounds of women with breast cancer. These consultations were held following scheduling, with an average of four women being attended per day.

The data were analyzed using Bardin's technique of categorization; a variant of classical content analysis, which allows the identification of the issues which emerge from the discourse ${ }^{(8)}$.

The analysis occurred in three stages, as stipulated by the method adopted. The first stage was that of pre-analysis - known as skim reading generating initial impressions regarding the material to be analyzed. The second stage was exploration of the material - when the information is codified, creating the registration units. This stage guided the formation of preliminary categories by the researcher. In the third and last stage - that of the treatment and interpretation of the results - the previously-identified information is compacted and highlighted, after which analysis occurs, culminating in the organized, reflexive and critical interpretation of the data, substantiating final interpretations ${ }^{(8)}$. Four categories were formed: outpatient attendance as a subspecialty of oncology nursing; the formation of bonds in the outpatient space; the fungating wound in the breast: disfiguration of the woman's body and self-esteem, challenging and frustrating care for the nurse; and indications for the assistential nursing practice.

The statements are referred to in the text using numerical identification preceded by the letter "P", which designates the condition of participants in the research, so as to preserve anonymity. Prior to holding the interview, there was an intentional invitation to participate in the study, with the objectives being explained and the Terms of Free and Informed Consent being provided.

The study was submitted to the Research Ethics Committee of the Brazilian National Cancer Institute (INCA, in Portuguese) and was approved under Decision CEP INCA 132/09, as it complied with the requirements of Resolution 196/96 of the Brazilian National Health Council (CNS, in Portuguese).

\section{Results}

The population interviewed was made up of five nurses, all female, with a mean age of 30 years old, and who corresponded to the total number of nurses allocated to the dressings room in the outpatient department of the institution where data collection occurred. All had undertaken lato sensu specialization courses in clinical areas. Two nurses had specialist qualifications in Oncology Nursing, of whom one received her qualification through practical training offered by the hospital institution where the research was undertaken, and the other through an academic course. Among the other nurses, one has a nursing qualification in stoma care: a professional with expertise in wounds and care for ostomies. The mean length of time since qualification was 12 years, and the mean length of experience was eight years.

Categories, described below, were produced from the final analysis of the interviewees' narrative.

\section{Outpatient attendance as a subspecialty of Oncology Nursing}

Being an oncology nurse was indicated as a requirement which qualifies the practice in the caring for women with breast cancer and with a resulting malignant fungating wound, as exemplified in the report of one of the nurses who does not have this specialty: Being a nurse and being specialized in oncology is very important. We feel the difference. Often, we go to them [the oncology nurses] to clarify doubts (P2). 
One of the oncology nurses stated: You act with greater confidence and understanding of the assistance for the clients when you have this specialty (P1). In this way, the recognition occurs of the importance of the specialized training, complementary to the undergraduate course, for providing nursing care in oncology.

The mode of outpatient attendance is indicated as a clinical specialty which distinguishes them, as exemplified in the following account: We are different (P2). Another nurse sought to explain this difference in terms of the clients' therapeutic trajectory in the institution: The difference is, that in the outpatients unit, the woman goes home, and the proposal is to cure her (P1).

The designation of Outpatient Oncology Nurses is a new term, is not usual, and is not formally recognized in the ambits of the specialities of Nursing by the professional regulator ${ }^{(9)}$.

\section{The forming of bonds in the outpatient space}

The bond is present strikingly in these nurses' discourse. One of them even related it to the specific character of the outpatient department: The specific clinic which strengthens the bond (P3).

Some nurses, with sadness in their eyes and their heads bowed, mentioned a more sombre aspect of this experience, described in the following observation, verbalized with striking emotion, regarding the forming of bonds: There is the side of bonding, but there is the negative side we face, which is to follow the progression of the worsening [of the disease], as well (P5).

Accompanying the "progression of the worsening" of the disease leads to interaction with the inpatient unit, where they go to seek information on the trajectory of the women attended: We asked about them, because we wanted to know how they were. We consulted our colleagues in the inpatient unit, going there or asking when we met them (P2).

The professional-technical and affective care measures, associated with the comfort of the environment and the spaces for expressing feelings and communication, are actions which contribute to the link between health professionals and their patients. Allowing oneself to be emotionally affected is an important part of the therapeutic meeting which often occurs in the outpatient monitoring of the process of the progression of the disease ${ }^{(10)}$.

As an example of this, one of the nurses described the situation of a patient who became pregnant and continued with the pregnancy as the disease progressed, with a consequent worsening of the fungating wound in her breast. She debated issues regarding the patient's motherhood and regarding herself with empathy and emotion: The patient said to us: I see my daughter in the crib and I can't hold her because of the infection and the bad smell from this wound (P1). Following that, she wondered: Everyone: I have two children and I asked myself, how could she bear that?! (P1).

The nurses' empathy may also be exemplified in the narrative below, which refers to the issue of gender: The woman who cares for a woman seems to suffer more (P3). The self-care appeared as a concern in the words of another nurse: Often, when we are applying these dressings, we put ourselves in the place of these women, and we would not like to be there (P5). Reflecting on this experience, another participant reported: I am always worried about going for my mammography, which I haven't done yet, but it worries me. I can't relax. Outpatients does that to you (P4).

One study which investigated issues of gender, work and health among nursing professionals indicated that the high lack of adherence to measures for the early detection of breast cancer and cervical cancer among the professionals of this class is associated, as well as with the question of work overload, with issues of social, emotional and affective support. It also indicates that social relationships, such as those with work colleagues, health professionals, family and friends, can support the strategies of adherence to preventive practices ${ }^{(11)}$. Thus, the social bond between the nurses, and the affective bond which forms between them and their patients, can promote the formation of the social environment which allows greater motivation for the health professional to care for herself. 
The fungating wound in the breast: disfiguration of the woman's body and self-esteem, challenging and frustrating care for the nurse

The nurses recognize the wound's disfiguring impact on the female body, as may be observed in the following statement: For the woman with a wound in her breast, it is like a cut on the face (P3). Another nurse stated: It is like a monster attached to the body (P1).

When the woman has a fungating wound resulting from breast cancer, her body is altered by the disease, by the treatment and - in addition - by the imposed wound. As a result, nausea, vomiting, alopecia, fatigue, weight gain or loss, effects on the skin and sexual dysfunction ${ }^{(12)}$ can coexist in a body altered by the mutilation imposed by the mastectomy and/or by the disfiguration caused by the advance of a wound proliferating through the thoracic-mammary region destructively and expansively, with the exudate, a fetid odor, and pain and bleeding. It may be inferred that, under these circumstances, the body image is violently changed.

The physical degradation of the breast, and the degradation of the woman's self-esteem, were indicated as factors which also penalize the nurses' experience and cause a feeling of "frustration" in their practice, as shown in the narrative of one of the nurses: It's a wound which destroys self-esteem, segregates the others, and disfigures the breast. It is frustrating to care for (P5). The frustration is explained by the nurses as resulting from the fact that the women wish for the fungating wound to heal, and this causes an emotional demand for the nurses, as explained in the accounts below: It's frustrating to care for (P2). There are patients who even note down the wound surface measurements (P3). We avoid the subject (P4). It's difficult to deal with this (P5).

As a result of the advance of the oncological disease, of the clinical interventions and of the fact that the results expected for the malignant fungating wounds are restricted to the paradigms of symptom control, the current strategies are the prevention of further deterioration of the tissues and the maintenance of the person's dignity, such that the goal to be achieved is quality of life ${ }^{(13)}$ rather than the healing of the wound.

In relation to the difficulties of managing this wound, the doubts relate to the handling and control of the signs and symptoms. The cleaning of the fungating wound was mentioned by one of the nurses: It's practically a bath in the room, the wounds are extensive (P2). The doubts resulted from the friability of the wound in relation to the use of topical products, as the following narrative reveals: I use mineral oil. There are doubts, but it's what I use on the friable wounds (P2).

Debridement was mentioned by all the participants as a procedure to be adopted carefully, as the following statement shows, undertaken by the stomatherapy nurse who was a member of the group: autolytic debridement, mechanical, instrumental, we have all that. But the dressings must be used very carefully (P3).

As a result of the gap in technical knowledge relating to fungating wounds, some clinical interventions are not consensual. Debridement and the control of the odor are two issues which remain controversial. In relation to the former, the fact is due to the risk of bleeding which such wounds have, explained by the friability which is intrinsic to the development of the malignant tumor. In this regard, the Brazilian literature states the total contraindication of surgical debridement and of the use of enzymatic debriding collagenase ointment, which is a promoter of granulation and epithelialization ${ }^{(14)}$.

In relation to the odor which emanates from these wounds, the same was cited by all the nurses as the symptom which is most difficult to control, as the following account illustrates: The challenge is to control the odor (P1). There was consensus that the odor disturbs patients and professionals, as the following account shows: The odor? God! It bothers the patient and even us! (P3).

The existential suffering and the embarrassment which the odor from these wounds impose upon the individual with cancer, her family members and the health professionals themselves are recognized in the international literature; also recognized are the 
difficulties in controlling them, and the weak evidence for the methods available for this ${ }^{(13)}$. In this regard, one of the oncology nurses mentioned the importance of the hygienic mastectomy; the removal of the breast with the objective of controlling the symptoms of the wound, or even of avoiding them, without any expectation of curing the disease. This is a palliative approach and depends on the patient's general state and life expectancy ${ }^{(15)}$.

Some nurses remembered various cases experienced, in which the control of the exudate and the odor were fruitless and caused extreme suffering to the woman. The following account exemplifies the empathy, the bonding and the involvement in the practice, and was expressed with strong emotion in the account in which the interviewee remembered one patient in particular, and, at the end of the narrative, questioned: I remember her, and I ask myself: why was she not referred for the hygienic mastectomy? If it had been approached at the start... (P1).

Trying to compose herself and control her emotions, she remembers: We got tired of seeing the person with the wound for years, without having the operation! There was one patient who did it, and, sometimes, I think that it was the patient who insisted (P1). This same nurse also considered the specialized care in palliative care, available in the institution, as a possibility for referring the women with the disease at an advanced stage; a clinical situation in which the wound becomes more symptomatic; and she concluded her account in the following way: The time for palliating is lost on the way (P1).

\section{Indications for the assistential nursing practice}

The professional commitment and liking the practice which one undertakes were the first items indicated and were described as follows: First of all is to like it. Otherwise, you don't get involved, and it's gone. There has to be involvement (P1).

Liking what one does and deciding between becoming involved and not becoming involved are actions indicated in the literature as one of the ethical premises for the exercising of more humanized care, valuing care and interpersonal relationships ${ }^{(16)}$.

The nurses were concerned about the relationships in the ill woman's world. In this regard, emphasis was placed on the interventions with a social nature, as may be detected in the narratives below: The nurse encourages socializing, we tried to break taboos and encourage coexistence, self-esteem and the patient's image. And work, when the client is still working (P3).

The importance of forming therapeutic groups among patients was emphasized in the following narrative from one of the oncology nurses: Through undertaking therapeutic groups, the woman feels that she is next to an equal (P1).

Undertaking therapeutic groups is one of the types of instruments for achieving comprehensiveness of the health care, a fact which has gained space in the light of the Unified Health System's public policies of humanization and its guiding principles. In addition to the sociabilization which undertaking therapeutic groups allows, health education occurs through the individual and collective dialog, creating spaces for self-help, the exchanging of experiences, selfvalorization and self-esteem, in addition to generating knowledge which supports the establishment of conducts by the health professionals which are tailored to each woman ${ }^{(17)}$.

"Autonomy" was a major word used in the nurses' discourses. It appears referring to their professional activities in the workspace of the outpatient department, in the referral of patients to other professionals in the health team, in the relationship with the doctor, in the management of the wound and in the approach to the patients, as well as being a motivational factor for work in the outpatient department, as revealed in the next account: In the outpatient department, we have autonomy and the outpatient department is always looking for new technologies (P2).

Autonomy in the work is established by the regulation of the exercising of the profession. Competence, infrastructure and sharing/collective construction, emphasizing autonomy interacting 
with liberty and responsibility in taking decisions on a scientific basis, and in the achieving of the value of their social work, are intervenient factors indicated in the literature ${ }^{(18)}$. As a result of this, autonomy is associated with scientific knowledge, which feeds back into it.

In considering sharing/collective construction, the referral to other professionals appears in the discourse and is explained in the following account: There are issues which are beyond the nurses' capacity, so we refer them to any other professional who might be able to resolve them (P3). This same nurse emphasized the partnership with the doctors in the evaluation of the wound, stating that: Sometimes, the doctor has no idea of how the wound is. (P3). However, she pointed to difficulties in getting these professionals to collaborate through attending when they are called, a fact also reported by other nurses.

The lack of collaborative actions was mentioned as lack of collaboration from the doctor (P3). This same interviewee gave an example of the strategy used in such situations: I call, and I call, and when I can call no longer, I go there and I try to fetch him, because the patient needs him to look at the wound (P3). Another nurse's report summarizes the various discourses used to explain the need which they have for autonomy: We talk about autonomy, but everything is for the patient to improve. The patient improving motivates the health professional (P4).

The interpersonal relationships, in the strain created by the professional stress and in the risk inherent to the care, are factors which make the nurses' autonomy vulnerable ${ }^{(18)}$. Studies carried out specifically in oncology outpatient departments, investigating the medical-assistential practice, report that the level of the relationship between nurses and physicians can promote or inhibit the high quality of the assistential care provided ${ }^{(19)}$.

\section{Discussion}

Based on the discourses of the nurses who work applying dressings to malignant fungating wounds in women with breast cancer, the following were identified: feelings of satisfaction, difficulties, doubts and suggestions for improvements in the nursing care regarding the issue investigated.

The satisfaction is related to the work environment, the forming of the bond between peers and with the patients cared for, social distinction, scientific knowledge regarding new technologies, autonomy in the undertaking of daily care practice, and the perception of improvement in the patients as a result of the care given.

When the nurses report "professional autonomy", which is the expression cited most in the interviews after the word "bond", they focus on the necessary, albeit weak, partnership with the doctor for the benefit of the women attended in the outpatient department, because they believe in this professional's importance in the physical and psychological care directed towards the control of the malignant fungating wound's symptoms.

It is appropriate to emphasize that the interviewees characterize the specific character of the outpatient attendance through the forming of a bond with the woman. When the disease progresses and - as a consequence - the fungating wound worsens, the nurses come to term the care challenging and frustrating, pointing to the difficulties in the control of the management of the symptoms: friability; exudate and odor; difficulty in communicating with the woman, when she is hoping for the incurable wound to heal; and finally, personal discomfort caused by having to live, in her work practice, with the odor emanating from the malignant fungating wound.

The report reveals there to be harrowing doubts in relation to the hygienic mastectomy and the nurses' concern that the time for palliating is lost on the way, as stated by one of the participants. It appears that such doubts result from the lack of information and partnerships exchanged between physicians and nurses in the institution, the lack of a clinical protocol for managing the wounds, and the scarcity of investigations on the topic, which hinder the nurses' 
construction of knowledge.

It can be seen, however, that the distress is present because among these nurses, what predominates is the forming of a bond with the patients assisted and genuine professional involvement which humanizes the care which they provide, in their day-to-day routine, to the women who suffer from breast cancer; and, in addition, the sadness which the malignant fungating wound imposes on the process of being ill with an oncological disease, in an area of the female body which is so significant. The nurses want to mitigate this suffering and see the hygienic mastectomy as an important therapeutic strategy, although it is a strategy defined by the doctors. In this context, to have harrowing doubts is to have workrelated suffering, and this can be mitigated by the establishment of clinical protocols and the exchange of information between the teams.

Other suggestions for improvements of the assistential practice, verbalized or identified through the analysis of the report, relate to the need for a formal process of specialization of the nurses, ethical precepts, practices for forming the therapeutic group, and joint work with the medical team. Such suggestions give a broad character to the nursing care directed at this clientele.

Considering this study's findings, it may be inferred that the nurses recognize the physical, psychological and social harm which the wound imposes on the women with breast cancer. To the extent that they propose the undertaking of the therapeutic group as a means for promoting these women's socialization and self-esteem, the nurses recognize the need for holistic care, a type of care recommended in approaching people with malignant fungating wounds ${ }^{(3)}$.

When they describe the forming of bonds, the nurses infer a liking for the practice of care for this clientele and professional involvement, and demonstrate that they provide empathetic care, which is also indicated as necessary in the care context for this clientele. They also recognize the need for a palliative approach, as the scientific literature recommends ${ }^{(3,6)}$. This recognition is revealed through the concern which they mention in relation to the appropriate time for having the hygienic mastectomy, a medical procedure which could contribute to the reduction of drastic consequences resulting from the local progression of the disease, such as odor and disfiguration.

In investigating the universe of Swiss nurses who dealt with these women in the routine of their care practices, nurse researchers discovered that the greatest difficulty for those professionals was in the control of the fetid odor, followed by control of the pain and how to apply the dressing on the malignant fungating wound ${ }^{(3)}$. The nurses of the study described here have difficulties in controlling the odor. They state, however, that they are inserted in a professional environment equipped with technological resources, which allows the use of more effective products in the control of these wounds' symptoms, including the odor.

Researchers confirm that the selection of appropriate products for the dressing is the best strategy for controlling these wounds' symptoms. Furthermore, the management of the patients through guidelines, continuing professional education and the participation of nurses with expertise in wounds are strategies which, in fact, can improve the quality of the nursing care provided to the women with breast cancer aggravated by the fungating wound ${ }^{(3)}$.

The literature indicates that the mean length of coexistence of an individual with cancer with her malignant cutaneous fungating wound is approximately 12 to 56 months. During this time, the malignant fungating wound causes a reduction or decline of physical well-being. The individual affected becomes stigmatized and needs the "help" of a professional with expertise in wounds, because the individual herself struggles alone to manage her wound, using inefficacious strategies. It is the professional's assistance which allows the individual to live positively with a wound that will not heal. As 
a result, it is the care which the patient receives for her malignant fungating wound which enables her to adapt to co-exist with the cancer. This fact legitimates the need for the early insertion of a nurse who is an expert in wounds in the multidisciplinary oncology team ${ }^{(6)}$. The professional environment researched is again shown to be promising because one of the nurses there is qualified in stomatherapy - which certifies her to contribute in the process of improving the care provided.

The importance given to the outpatient department as a locus for specific practice, the indication of the specialization in Oncology Nursing and the holding of the therapeutic group were data which surprised the researchers in this study. It is noteworthy that the recommendation to form a therapeutic group was not found in the literature on the issue addressed here, being, therefore, a new datum.

This, study, however, is limited by the low number of participants and the fact that it involved only one hospital institution in only one model of care: that of outpatient care. However, the fact stands out that studies on the specific character of oncology nursing practice in outpatient departments are scarce worldwide ${ }^{(20-21)}$. Nevertheless, the recognition of the power to transform and improve the health system under the leadership of the nurses, promulgated by the American Institute of Medicine in the document titled "The Future of Nursing: Leading Change, Advancing Health", placed the way of caring for patients with cancer as an area of high priority to be redesigned in the health system due to this disease's complexity(20), which will certainly cause the outpatient environment to be increasingly investigated in studies exploring oncology nurses' practice and knowledge.

Thus, although this study is small-scale and incipient, it is a Brazilian production which presented issues inherent to the outpatient area and to the management of symptoms and nursing care in malignant fungating wounds: two subjects which are little-explored in literature worldwide. Equally, it also presented support which can be considered for improving assistential practices in the institution where the data were collected.

\section{Conclusion}

The nurses who work in outpatient care for women with fungating wounds in the breasts experience satisfaction, autonomy, challenges and professional frustrations in their work routine. They have doubts regarding the technical-professional care used in the control of these wounds' symptoms, and are bothered by the odor emanating from these. Nevertheless, they base their actions in a humanistic vision of the ill woman, experiencing feelings of empathy and the forming of bonds through this.

The nurses show compassionate interaction with this clientele, and indicate the undertaking of therapeutic groups for self-help. In providing the nursing care, they seek greater partnership with the medical team and wish to broaden the palliative approach through the hygienic mastectomy, as a means of prevention and control of the symptoms and suffering of the women with breast cancer. As outpatient nurses, they defend the professional autonomy in favor of the clientele which they attend. They indicate specialization in Oncology Nursing, technical skill, professional involvement and liking the practice which is undertaken as requirements for improving the assistential practice.

\section{Collaborations}

Firmino F participated in the conception and development of the project, in the collection and analysis of the data, and in the editing and critical analysis of the article. Alcântara LFFL participated in the editing and critical analysis of the article.

\section{References}

1. Probst S, Arber A, Faithfull S. Malignant fungating 
wounds: a survey of nurses'clinical practice in Switzerland. Eur J Oncol Nurs. 2009; 13(4):295-8.

2. Haisfield-Wolfe ME, Baxendale-Cox LM. Staging of malignant cutaneous wounds: a pilot study. Oncol Nurs Forum. 1999; 26(6):1055-64.

3. Probst S, Arber A, Faithfull S. Malignant fungating wounds: the meaning of living in an unbounded body. Eur J Oncol Nurs. 2013; 17(1):38-45.

4. Agra G, Fernandes MA, Platel ICS, Freire MEM. Cuidados paliativos ao paciente portador de ferida neoplásica. Rev Bras Cancerol. 2013; 59(1):95104.

5. Probst S, Arber A, Trojan A, Faithfull S. Caring for a loved onde with a malignant fungating wound. Eur J Oncol Nurs. 2012; 20(12):3065-70.

6. Lo S, Hu WY, Hayter M, Chang SC, Hsu MY, Wu LY. Experiences of living with a malignant fungating wound: a qualitative study. J Clin Nurs. 2008; 17(20):2699-708.

7. Gaskell G. Entrevistas individuais e grupais. In: Bauer MW, Gaskell G, editores. Pesquisa qualitativa com texto, imagem e som: um manual prático. $2^{\underline{a}}$. ed. Rio de Janeiro:Vozes; 2003.

8. Bardin L. Análise de conteúdo. Lisboa: Edições 70; 2011.

9. Conselho Federal de Enfermagem. Resolução 389 de 18 de outubro de 2011. Atualiza, no âmbito do Sistema Cofen/Conselhos Regionais de Enfermagem, os procedimentos para registro de título de pós-graduação lato e stricto sensu concedidos a Enfermeiros e lista as Especialidades. Brasília, 20 out. 2011. Seção 1, fl. 146.

10. Moura MMD, Guimarães MBL, Luz M. Touch: attention to the bounds in the hospital setting. Interface. 2013; 17(45):393-404.

11. Silva IT, Girep RH, Rotenberg L. Social support and cervical and breast cancer screening practices among nurses. Rev Latino-Am Enfermagem. 2009; 17(4):514-21.
12. Oliveira CL, Sousa FPA, Garcia CL, Mendonça MRK, Menezes IRA, Brito Júnior FE. Câncer e imagem corporal: perda da identidade feminina. Rev Rene. 2010; 11(n. esp.):53-60.

13. Grocott P, Gethin G, Probst S. Malignant wound management in advanced illness: new insights. Curr Opin Support Palliat Care. 2013; 7(1):101-5.

14. Matsubara MGS. Feridas neoplásicas. In: Matsubara MGS, Villela DL, Hashimoto SY, Reis HCS, Saconato RA, Denardi UA, et al. Feridas e estomas em oncologia. Uma abordagem interdisciplinar. São Paulo: Lemar; 2012.

15. Figueiredo JCA, Rosique RG, Maciel PJ. Tração cutânea intraoperatória para fechamento de ferida após mastectomia bilateral higiênica: relato de caso. Rev Bras Cir Plást. 2011; 26(1):164-6.

16. Puggina ACG, Silva MJP. Ética no cuidado e nas relações: premissas para um cuidar mais humano. Rev Min Enferm. 2009; 13(4):599-605.

17. Pereira QLC, Siqueira HCH. Grupo terapêutico de autoajuda à mulher climatérica: uma possibilidade de educação. Rev Min Enfer. 2009; 13(4):593-8.

18. Menezes SRT, Priel MR, Pereira LL. Nurse's autonomy and vulnerability in the nursing assistance systematization practice. Rev Esc Enferm USP. 2011; 45(4):953-8.

19. Friese CR, Manojlovich M. Nurse-physician relationships in ambulatory oncology settings. J Nurs Scholarsh. 2012; 44(3):258-65.

20. Friese CR, Himes-Ferris L. Nursing practice environments and job outcomes in ambulatory oncology settings. J Nurs Adm. 2013; 43(3):14954.

21. Kamimura A, Scheider K, Lee CS, Crawford SD, Friese C. Practice Environments of nurses in ambulatory oncology settings: a thematic analysis. Cancer Nurs. 2012; 35(1):1-7. 